\title{
Short term exposure to airborne microbial agents during farm work: exposure-response relations with eye and respiratory symptoms
}

\author{
W Eduard, J Douwes, R Mehl, D Heederik, E Melbostad
}

\begin{abstract}
Objectives-Exposure to high levels of non-infectious microbial agents is recognised as a cause of respiratory disease in working populations, but except for endotoxins, little is known about exposureresponse relations. As these effects do not depend on viability, exposure to nonviable microbial agents is important. Various methods not based on microbial cultures were explored to study the complex microbial exposure of farmers and associations with acute symptoms during work.
\end{abstract}

Methods-Airborne exposure was measured when farmers carried out specific tasks. Fungal spores, bacteria, endotoxins, $\beta(1 \rightarrow 3)$-glucans, fungal antigens specific for Penicillium and Aspergillus species, and mites were measured by methods not based on microbial cultures. Also silica, inorganic and organic dust, ammonia, hydrogen sulphide, and nitrogen dioxide were measured. Respiratory, and nose and eye symptoms experienced during measurements were recorded by a short questionnaire. Both univariate and multivariate statistical analyses were applied to assess the relations between exposure and acute symptoms.

Results-106 Farmers and their spouses participated in this study. Prevalences of work related symptoms were: wheezing $3 \%$; chest tightness $7 \%$; cough $14 \%$; eye symptoms $18 \%$; and nose symptoms $22 \%$. Prevalence ratios for nose and eye symptoms were 4-8 after exposure to $20-500 \times 10^{3}$ fungal spores $/ \mathrm{m}^{3}$ and higher, and a prevalence ratio for cough was 4 after exposure to $500-17000 \times 10^{3}$ fungal spores $/ \mathrm{m}^{3}$. Nose symptoms were also associated with exposure to silica with prevalence ratios of 4-6 after exposure to $0.015-0.075 \mathrm{mg} / \mathrm{m}^{3}$ and higher.

Conclusions-Farmers had a high occurrence of symptoms of the nose and eyes as well as cough during work. These symptoms were associated in a dose dependent manner with exposure to fungal spores. Nose symptoms were also associated with exposure to silica.

(Occup Environ Med 2001;58:113-118)

Keywords: bioaerosols; exposure; fungal spores; work related symptoms; respiratory effects; exposureresponse
Non-infectious microorganisms and microbial agents such as bacterial endotoxins are known to cause respiratory effects through toxic and immunological mechanisms. In various working populations asthma, chronic obstructive pulmonary disease, extrinsic allergic alveolitis, and organic dust toxic syndrome (febrile episodes with transient lung function changes not associated with occupational asthma or extrinsic allergic alveolitis) are associated with inhalation of airborne microorganisms. ${ }^{1}$ Although the causal role of microbial exposure in the development of disease is often clear, information on exposure-response relations is limited. Currently, epidemiological and experimental studies have given sufficient support for the development of a proposal for an occupational exposure limit only for endotoxins. ${ }^{2}$

One reason is that exposure assessment is extremely difficult and several methods have been used, many of which have only limited use for quantitative assessment of microbial exposures. Especially, methods based on microbial cultures have been used extensively. Although important information on microbial species has been obtained measurement data are at best semiquantitative. This is because of short sampling time, selective detection of groups of viable microorganisms, and stationary sampling, and application of such techniques in large scale epidemiological studies is expensive due to the complicated logistics. Health effects typical for exposure to non-infectious microbial agents are usually not dependent on viability of microorganisms but are caused by such specific agents as allergens and toxins that are present in both viable and non-viable microorganisms. In epidemiological studies it is therefore often more relevant to measure the total microbial burden, including viable and nonviable bacteria or fungi, or markers of this burden rather than the fraction that can be cultured. $^{3}$

Recently, application of methods not based on microbial cultures such as $\beta(1 \rightarrow 3)$-glucans, fungal spores, bacteria, and $\alpha$-amylase gave promising results in studies of respiratory effects in different populations-for example, in sick buildings, ${ }^{45}$ sawmill workers, ${ }^{6}$ sewage workers, ${ }^{7}$ bakers, ${ }^{8}$ and household waste collectors. $^{9}$ Application of techniques not based on microbial cultures seems therefore promising in combination with the advantage of simple sampling of these constituents by conventional collection on filters.

We explored methods not based on microbial cultures for the measurement of microbial 
agents to study the complex bioaerosol exposure of farmers. Airborne fungal spores, $\beta(1 \rightarrow 3)$-glucans, endotoxins, bacteria, and mites (from fire dust) were measured as possible inflammatory agents, and fungal extracellular polysaccharides of Penicillium and Aspergillus (EPS-Asp/Pen) were measured as markers of fungal exposure. Also, we measured airborne silica, and inorganic and organic dust. The study was nested in a cross sectional study of respiratory diseases in Norwegian farmers. ${ }^{10}{ }^{11}$ In the present paper we report associations between exposure and acute work related eye and respiratory symptoms. Both univariate and multivariate analyses were carried out to identify the most important agents.

\section{Materials and methods}

SAMPLING STRATEGY

A total of 290 farms were randomly selected among the participants of a cross sectional study of farmers in three counties of south eastern Norway. ${ }^{10}$ Farms were located in coastal, inland, and mountainous regions (altitude up to $1000 \mathrm{~m}$ ) all within a $350 \mathrm{~km}$ radius of the institute. Farmers and their spouses were invited to participate in the present study. Due to retirement (11\%), unwillingness to participate $(4 \%)$, or logistic constraints $(41 \%)$, measurements were performed on 127 farms. Personal exposure measurements were carried out in 1992-6 during all seasons. Exposure was measured when specific exposed tasks were being carried out. The sampling time was equal to the duration of the task with an upper limit of 1 hour if the task lasted longer. Tasks included handling of harvest (grain, hay, straw, silage, potatoes, and onions), animal tending (cattle, swine, poultry, sheep, and goats), and handling of manure. When feasible different tasks were measured on the same farm.

AEROSOL SAMPLING

Each personal exposure measurement consisted of collecting three separate total dust samples simultaneously on polycarbonate filters with pore size $0.4 \mu \mathrm{m}$ (Poretics, Osmonics, Livermore, CA, USA) in closed face $25 \mathrm{~mm}$ diameter aerosol monitors made of graphite filled polypropylene with portable battery powered pumps (AFC 123, Casella, London, UK). From each exposure measurement one filter was used for the measurement of the total mass, spores, and chemical particle types, one filter for the measurement of bacteria, and one filter for the measurement of endotoxins, glucans, and fungal antigens.

TRANSPORT AND STORAGE OF AEROSOL SAMPLES Samples were transported to the laboratory at ambient temperature, usually within 72 hours. Samples were stored at the laboratory before analysis at $4^{\circ} \mathrm{C}$ for fluorescence microscopy, at ambient temperature for scanning electron microscopy and at $-25^{\circ} \mathrm{C}$ for analyses of endotoxins, $\beta(1 \rightarrow 3)$-glucans, and fungal antigens (EPS-Asp/Pen).
ANALYSIS OF AEROSOL SAMPLES

Total dust was measured gravimetrically (Satorius ultra-microbalance model S4, Goettingen, Germany). After gravimetry, samples were resuspended in filtered Tween 80 solution (0.05\% weight/volume) after weighing for 3 minutes in an ultrasonic bath (Sonorex RK510H, Bandelin Electric, Berlin, Germany). Two adequate aliquots were filtered through polycarbonate filters with pore size 0.4 $\mu \mathrm{m}$ for counting of spores from fungi and actinomycetes by scanning electron microscopy, ${ }^{12}$ and analysis of organic, silicon rich (classified as silica) and other inorganic particles with scanning electron microscopy combined with electron dispersive spectrometry. ${ }^{13}$ Bacteria were analysed by fluorescence microscopy as already described. ${ }^{14}$ Endotoxins were analysed by a kinetic chromogenic Limulus amoebocyte lysate assay, ${ }^{15} \beta(1 \rightarrow 3)$-glucans by an inhibition enzyme immunoassay, ${ }^{16}$ and genus specific extracellular polysaccharides of Aspergillus and Penicillium (EPS-Asp/Pen) by a sandwich enzyme immunoassay. ${ }^{17}$

MITE SAMPLING AND ANALYSIS

Accumulated fine dust in materials that were handled by the farmer during the personal sampling and settled dust deposits relevant to the work were collected in polyethylene containers. A few drops of ethyl acetate were added to kill mites and samples were stored at $-25^{\circ} \mathrm{C}$ before analysis. The dust fraction $<500 \mu \mathrm{m}$ was sieved out for mite analysis by microscopy as described elsewhere. ${ }^{18}$ Based on the mite concentration in fine dust the airborne concentration was estimated by multiplying the number of mites found/mg of dust $<500 \mu \mathrm{m}$ with the airborne organic dust concentration (mite units $/ \mathrm{m}^{3}$ ).

MEASUREMENT OF BIOGENIC GASES

Hydrogen sulphide and nitrogen dioxide were measured continously with personal electrochemical data logging monitors, PM-7700 with sensors gs-7702 and gs-7705 respectively (Metrosonics, USA). Ambient spot concentrations of ammonia were measured with detector tubes for ammonia type 2/a (Dräger AG, Lübeck, Germany) positioned as close as possible to the farmer. Gas measurements were not performed when sources of exposure and odour were absent because the exposure was then assumed to be negligible.

\section{QUESTIONNAIRES}

Information on age, sex, smoking habits (active, former, and never smokers), and allergy (defined as diagnosis by a doctor, admission to hospital, or medical treatment because of allergic disease) were obtained from a general questionnaire used in the cross sectional study. ${ }^{10}$ Symptoms experienced during work on the day that exposure was measured, were recorded by a short questionnaire that was completed directly after the measurements. Use of respiratory protection was also recorded. 
Table 1 Characteristics of the population

\begin{tabular}{lll}
\hline & Population & \\
\cline { 2 - 3 } Characteristic & Exposure study & Cross sectional study * \\
\hline Participants (n) & 106 & 8482 \\
Age (y, mean (SD)) & $48(9)$ & $49(11)$ \\
Farm production (\%): & & \\
$\quad$ Livestock and crops & 83 & 73 \\
$\quad$ Exclusive crops & 17 & 27 \\
Sex (\%): & & \\
Female & 19 & 36 \\
$\quad$ Male & 81 & 64 \\
Smoking (\%): & & \\
$\quad$ Never smoker & 57 & 47 \\
$\quad$ Former smoker & 17 & 24 \\
$\quad$ Current smoker & 26 & 30 \\
Allergy (\%) & 18 & 20 \\
\hline
\end{tabular}

${ }^{\star}$ Source population

DATA ANALYSIS

Eight hour time weighted average (TWA) exposures were computed based on type and duration of task for each farmer. The TWA exposures included all tasks carried out by the participant during the measurement day until symptoms were recorded. Exposure data were roughly log normally distributed and were summarised by arithmetic means, geometric means, and geometric SDs. Pearson's correlation coefficients were calculated with log transformed data.

Exposure-response associations were studied in people that participated both in the cross sectional and the exposure study, and who did not use respiratory protection. If measurements had been performed on the same person on more than 1 day, the 1 st day was selected to avoid dependency of the data. If the participant had reported symptoms on 1 or more days, the 1st day with a positive response was selected. Exposure concentrations of each agent were categorised in tertiles. Associations between symptoms and exposures were estimated by prevalence ratios (PRs) using Cox's regression according to Thompson et al. ${ }^{19}$ The model assumes Poisson variability in the response variable and by defining the model for a closed cohort and a constant risk period, direct estimates of the PR can be obtained. The PR

Table 2 Personal exposure to microbial agents, dust, and ammonia during farm work (TWA exposure on the measurement day until symptoms were recorded)

\begin{tabular}{|c|c|c|c|c|}
\hline \multirow[b]{2}{*}{ Agent } & \multirow[b]{2}{*}{$n^{*}$} & \multicolumn{3}{|c|}{ TWA exposure ${ }^{\prime}$} \\
\hline & & $A M$ & $G M$ & $G S D$ \\
\hline Total dust $\left(\mathrm{mg} / \mathrm{m}^{3}\right)$ & 106 & 0.84 & 0.31 & 4.2 \\
\hline Organic dust $\left(\mathrm{mg} / \mathrm{m}^{3}\right)$ & 99 & 0.28 & 0.047 & 9.0 \\
\hline Silicon rich dust $\left(\mathrm{mg} / \mathrm{m}^{3}\right)$ & 99 & 0.081 & 0.021 & 7.8 \\
\hline Other inorganic dust $\left(\mathrm{mg} / \mathrm{m}^{3}\right)$ & 99 & 0.49 & 0.16 & 4.7 \\
\hline Fungal spores $\left(10^{6} / \mathrm{m}^{3}\right)$ & 106 & 1.2 & 0.099 & 16 \\
\hline Total bacteria $\left(10^{6} / \mathrm{m}^{3}\right)$ & 104 & 2.5 & 0.56 & 7.7 \\
\hline Rod shaped bacteria $\left(10^{6} / \mathrm{m}^{3}\right)$ & 99 & 0.22 & 0.024 & 11 \\
\hline Actinomycetes spores $\left(10^{6} / \mathrm{m}^{3}\right)$ & 106 & 一 & 一 & 一 \\
\hline Endotoxins $\left(10^{3} \mathrm{EU} / \mathrm{m}^{3}\right)$ & 105 & $13^{\top}$ & $1.2^{\top}$ & 14 \\
\hline$\beta(1 \rightarrow 3)$-glucans $\left(\mu \mathrm{g} / \mathrm{m}^{3}\right)$ & 90 & 6.4 & 0.82 & 14 \\
\hline EPS Pen/Asp $₫\left(\mathrm{mgeq} / \mathrm{m}^{3}\right)$ & 62 & 0.14 & 0.022 & 10 \\
\hline Mites (mite units $/ \mathrm{m}^{3}$ ) & 85 & 1.4 & 0.004 & 110 \\
\hline Ammonia $\|\left(\mathrm{mg} / \mathrm{m}^{3}\right)$ & 55 & 0.9 & 0.51 & 4.2 \\
\hline
\end{tabular}

*Number of measurements.

t8 $\mathrm{h}$ time weighted average exposure; $\mathrm{AM}=$ arithmetic mean; $\mathrm{GM}=$ geometric mean; $\mathrm{GSD}=$ geometric $\mathrm{SD}$.

$\ddagger$ Not estimated because of many data below detection limit.

§Extracellular polysaccharides specific for Penicillium and Aspergillus species.

-Surrogate measure, see the text.

$\|$ Ammonia was only measured when exposure was likely and otherwise assumed to be 0 in computation of cumulative exposure. can be calculated from the regression coefficient as $\exp (\mathrm{B})$. It is known that the SEM of the regression coefficient is an overestimation of the true SEM. ${ }^{19}$ As a result, $95 \%$ confidence intervals (95\% CIs) are wider and significance testing is more conservative. Regression models were constructed for each exposure variable separately adjusting for the following potential confounders: age (initially in four categories, but as dichotomising yielded similar results we chose to run all models dichotomised at 50 years), sex, and smoking habits. Models with two exposure variables were constructed when several exposure variables were associated with the same symptom. Associations with high prevalence ratios which did not reach significance were also considered as significance testing was conservative.

Statistical analyses were carried out with EGRET $^{7}$ 2.01, Cytel, Cambridge, MA, USA.

\section{Results}

STUDY POPULATION

The characteristics of the study population are shown in table 1. The proportion of women was lower than in the source population from the cross sectional study, and the proportions of never smokers and farmers with livestock production were higher. Age and allergy were similarly distributed. The number of farmers was lower than the number of farms visited, as tasks were also carried out by people not included in the study base-that is, relatives and hired workers.

\section{EXPOSURE}

TWA exposures to dust, dust components, and ammonia are shown in table 2. Other biogenic gases were detected only occasionally. Hydrogen sulphide was detectable in only seven out of 23 measurements with a range of $0.3-8$ $\mathrm{mg} / \mathrm{m}^{3}$ (peak values). Nitrogen dioxide was only measured during the handling of silage and was detected in five out of 22 measurements with a range of $0.5-0.8 \mathrm{mg} / \mathrm{m}^{3}$ (peak values). Exposure to microbial agents and mites showed very high variability as shown by large geometric SDs often indicating a range of more than four orders of magnitude (GSD>10).

Eight hour TWA exposures to different microbial agents were moderately to strongly correlated. The strongest correlation was found between total bacteria and rod shaped bacteria $(r=0.77)$, total bacteria and endotoxins $(r=0.68)$, and $\beta(1 \rightarrow 3)$-glucans and fungal spores $(r=0.67)$. Moderate to high correlations were also found between non-microbial and microbial agents; total dust was correlated with fungal spores, $\beta(1 \rightarrow 3)$-glucans, total bacteria, rod shaped bacteria, and endotoxins $(r=0.64-$ 0.79 ), and inorganic dust was correlated with total bacteria and endotoxins $(r=0.65-0.70)$. Other correlations were smaller than 0.60 .

WORK RELATED SYMPTOMS AND EXPOSURE Table 3 shows the prevalence of symptoms recorded directly after exposure measurements as well as the prevalence reported by the same participants in the cross sectional study . 
Table 3 Prevalence of work related symptoms among participants in the exposure study $(n=106)$

\begin{tabular}{llll}
\hline & \multicolumn{2}{c}{ Prevalence (\%) } \\
\cline { 2 - 4 } & \multicolumn{3}{c}{$\begin{array}{l}\text { Recorded in cross } \\
\text { sectional study }\end{array}$} \\
\cline { 2 - 4 } Symptom & $\begin{array}{l}\text { Recorded after } \\
\text { measurements }\end{array}$ & Often & Seldom \\
\hline Eye irritation or red eyes & 18 & 9 & 32 \\
Running or clogged nose & 22 & 18 & 36 \\
Cough & 14 & 12 & 24 \\
Chest tightness & 7 & 7 & 17 \\
Wheezing & 3 & 5 & 8 \\
\hline
\end{tabular}

Associations between symptoms and single exposure variables adjusted for sex, age, and smoking are shown in table 4. Allergy was not adjusted for as the prevalence of symptoms of the nose and eye as well as cough was almost the same in participants with and without allergy. The prevalence of wheezing and chest tightness was higher among allergic participants $(24 \% v 13 \%)$ but no major differences were found when allergy was included in the multivariate model. Cough was only significantly associated with the highest exposure category of fungal spores with a PR of 3.9, and other associations were weaker. Symptoms of the eyes were significantly associated with the medium exposure category of fungal spores with a PR of 8.3. The PR of the highest exposure category was also high, 7.0, but this association did not reach significance. Exposure to inorganic dust showed high but non-significant PRs for symptoms of the eyes. A model with fungal spores and inorganic dust (table 5) showed lower but still high PRs for both variables indicating that the nonsignificant association with inorganic dust is only partly due to exposure to fungal spores. Symptoms of the nose were significantly associated with the highest exposure categories of endotoxins, fungal spores, and silica, and both the medium and high exposure categories of total dust with PRs of 4-6. Models with combinations of two exposure variables are shown in table 5. Bivariate exposure models (adjusted for potential confounders) showed that all PRs were lower than those in univariate exposure models. The PRs were lowest for exposure to endotoxins and the PRs for the highest exposure group were lower than the PRs for the medium exposure group in all models with total dust. Exposure to fungal spores and silica seemed to be most consistently associated with nose symptoms.

\section{Discussion}

In this study of Norwegian farmers exposureresponse associations were found between acute work related symptoms and exposure to fungal spores, endotoxins, total dust, and silica. Among these exposures fungal spores showed the strongest associations with eye symptoms and cough whereas both fungal spores and silica were of equal importance for the

Table 4 Prevalence ratios of acute symptoms for individual exposure variables adjusted for sex, smoking, and age by Cox's regression

\begin{tabular}{|c|c|c|c|c|c|c|c|}
\hline \multicolumn{4}{|l|}{ Exposure } & \multicolumn{4}{|c|}{ Prevalence ratio $(95 \% \mathrm{CI})^{*}$} \\
\hline Agent & Category & TWA concentration & $n \dagger$ & $\begin{array}{l}\text { Red or irritated eyes } \\
\text { (cases }=16)\end{array}$ & $\begin{array}{l}\text { Running or clogged } \\
\text { nose (cases }=19-21 \text { ) }\end{array}$ & $\begin{array}{l}\text { Cough } \\
\text { (cases=15) }\end{array}$ & $\begin{array}{l}\text { Chest tightness or } \\
\text { wheezing (cases=11) }\end{array}$ \\
\hline \multirow[t]{3}{*}{ Bacteria } & Low & $0.002-0.3 \times 10^{6} / \mathrm{m}^{3}$ & 87 & 1 & 1 & 1 & 1 \\
\hline & Medium & $0.3-2 \times 10^{6} / \mathrm{m}^{3}$ & & $2.3(0.57$ to 9.0$)$ & $1.4(0.42$ to 4.8$)$ & $0.61(0.16$ to 2.3$)$ & $0.49(0.11$ to 2.1$)$ \\
\hline & High & $2-25 \times 10^{6} / \mathrm{m}^{3}$ & & $2.0(0.47$ to 8.8$)$ & $2.4(0.71$ to 7.8$)$ & $1.2(0.35$ to 4.3$)$ & $0.59(0.14$ to 2.5$)$ \\
\hline \multirow[t]{3}{*}{ Endotoxins } & Low & $0.01-0.25 \times 10^{3} \mathrm{EU} / \mathrm{m}^{3}$ & 89 & 1 & 1 & 1 & 1 \\
\hline & Medium & $0.25-5 \times 10^{3} \mathrm{EU} / \mathrm{m}^{3}$ & & $1.5(0.35$ to 6.4$)$ & $1.9(0.46$ to 7.5$)$ & $0.33(0.06$ to 1.8$)$ & $0.49(0.11$ to 2.1$)$ \\
\hline & High & $5-110 \times 10^{3} \mathrm{EU} / \mathrm{m}^{3}$ & & $2.3(0.61$ to 8.7$)$ & $4.1(1.1$ to 15$)$ & $1.6(0.53$ to 5.1$)$ & $0.78(0.21$ to 2.9$)$ \\
\hline \multirow{3}{*}{ Rod shaped bacteria } & Low & $0.000-0.02 \times 10^{6} / \mathrm{m}^{3}$ & 85 & 1 & 1 & 1 & 1 \\
\hline & Medium & $0.02-0.2 \times 10^{6} / \mathrm{m}^{3}$ & & $0.18(0.02$ to 1.5$)$ & $1.5(0.46$ to 4.7$)$ & $0.97(0.23$ to 4.2$)$ & $0.40(0.08$ to 1.9$)$ \\
\hline & High & $0.2-3 \times 10^{6} / \mathrm{m}^{3}$ & & $0.98(0.34$ to 2.9$)$ & $2.0(0.67$ to 5.7$)$ & $2.0(0.61$ to 6.8$)$ & $0.69(0.17$ to 2.7$)$ \\
\hline \multirow{3}{*}{ Fungal spores } & Low & $0.000-0.02 \times 10^{6} / \mathrm{m}^{3}$ & 89 & 1 & 1 & 1 & 1 \\
\hline & Medium & $0.02-0.5 \times 10^{6} / \mathrm{m}^{3}$ & & $8.3(1.0$ to 70$)$ & $4.1(0.88$ to 19$)$ & $1.3(0.28$ to 5.7$)$ & 0.38 (0.07 to 2.0$)$ \\
\hline & High & $0.5-17 \times 10^{6} / \mathrm{m}^{3}$ & & $7.0(0.83$ to 59$)$ & $6.0(1.3$ to 28$)$ & $3.9(1.0$ to 15$)$ & $1.7(0.50$ to 5.5$)$ \\
\hline \multirow[t]{3}{*}{$\beta(1 \rightarrow 3)$-glucans } & Low & $0.00-0.5 \mu \mathrm{g} / \mathrm{m}^{3}$ & 74 & 1 & 1 & 1 & 1 \\
\hline & Medium & $0.5-5 \mu \mathrm{g} / \mathrm{m}^{3}$ & & $1.4(0.32$ to 5.7$)$ & $2.2(0.69$ to 7.0$)$ & $1.4(0.37$ to 5.4$)$ & $0.61(0.12$ to 3.2$)$ \\
\hline & High & $5-76 \mu \mathrm{g} / \mathrm{m}^{3}$ & & $1.4(0.36$ to 5.3$)$ & $1.9(0.57$ to 6.1$)$ & $1.4(0.38$ to 5.0$)$ & $1.4(0.39$ to 5.2$)$ \\
\hline \multirow[t]{3}{*}{ EPS-Asp/Pen } & Low & $0.000-0.01 \mathrm{mgeq} / \mathrm{m}^{3}$ & 51 & 1 & 1 & 1 & 1 \\
\hline & Medium & $0.01-0.1 \mathrm{mgeq} / \mathrm{m}^{3}$ & & $1.4(0.18$ to 11$)$ & $1.0(0.21$ to 5.0$)$ & $1.0(0.14$ to 6.9$)$ & $0.96(0.18$ to 5.1$)$ \\
\hline & High & $0.1-1.1 \mathrm{mgeq} / \mathrm{m}^{3}$ & & $0.98(0.12$ to 8.1$)$ & $2.1(0.42$ to 11$)$ & $1.1(0.12$ to 9.5$)$ & $0.64(0.10$ to 4.1$)$ \\
\hline \multirow[t]{3}{*}{ Mites } & Low & $0.0000-0.0005$ mite units $/ \mathrm{m}^{3}$ & 73 & 1 & 1 & 1 & 1 \\
\hline & Medium & $0.0005-0.05$ mite units $/ \mathrm{m}^{3}$ & & $0.63(0.17$ to 2.3$)$ & $0.70(0.23$ to 2.1$)$ & $0.53(0.12$ to 2.2$)$ & $1.0(0.32$ to 3.4$)$ \\
\hline & High & $0.05-44$ mite units $/ \mathrm{m}^{3}$ & & $0.31(0.06$ to 1.6$)$ & $0.93(0.31$ to 2.8$)$ & $1.4(0.37$ to 5.1$)$ & $0.20(0.02$ to 1.7$)$ \\
\hline \multirow[t]{3}{*}{ Organic dust } & Low & $0.000-0.03 \mathrm{mg} / \mathrm{m}^{3}$ & 84 & 1 & 1 & 1 & 1 \\
\hline & Medium & $0.03-0.2 \mathrm{mg} / \mathrm{m}^{3}$ & & $0.88(0.24$ to 3.3$)$ & $0.88(0.29$ to 2.7$)$ & $0.46(0.09$ to 2.4$)$ & 0.37 (0.07 to 1.9$)$ \\
\hline & High & $0.2-6.8 \mathrm{mg} / \mathrm{m}^{3}$ & & $1.1(0.28$ to 4.0$)$ & $1.5(0.51$ to 4.2$)$ & $2.1(0.61$ to 6.9$)$ & $1.0(0.28$ to 3.6$)$ \\
\hline \multirow{3}{*}{ Dust } & Low & $0.007-0.15 \mathrm{mg} / \mathrm{m}^{3}$ & 89 & 1 & 1 & 1 & 1 \\
\hline & Medium & $0.15-0.5 \mathrm{mg} / \mathrm{m}^{3}$ & & $2.5(0.65$ to 10$)$ & $5.4(1.2$ to 25$)$ & $0.80(0.18$ to 3.6$)$ & $0.93(0.22$ to 3.9$)$ \\
\hline & High & $0.5-9.3 \mathrm{mg} / \mathrm{m}^{3}$ & & $1.5(0.37$ to 6.2$)$ & $5.0(1.1$ to 23$)$ & $2.1(0.61$ to 7.1$)$ & $1.1(0.27$ to 4.9$)$ \\
\hline \multirow[t]{3}{*}{ Inorganic dust $\ddagger$} & Low & $0.001-0.1 \mathrm{mg} / \mathrm{m}^{3}$ & 84 & 1 & 1 & 1 & 1 \\
\hline & Medium & $0.1-0.3 \mathrm{mg} / \mathrm{m}^{3}$ & & $6.7(0.76$ to 59$)$ & $3.6(0.95$ to 14$)$ & $0.52(0.12$ to 2.3$)$ & 0.69 (0.17 to 2.8$)$ \\
\hline & High & $0.3-6.8 \mathrm{mg} / \mathrm{m}^{3}$ & & $6.8(0.75$ to 62$)$ & $3.0(0.75$ to 12$)$ & $1.2(0.33$ to 4.6$)$ & $0.73(0.16$ to 3.3$)$ \\
\hline \multirow[t]{3}{*}{ Silica } & Low & $0.000-0.015 \mathrm{mg} / \mathrm{m}^{3}$ & 84 & 1 & 1 & 1 & 1 \\
\hline & Medium & $0.015-0.075 \mathrm{mg} / \mathrm{m}^{3}$ & & $1.3(0.39$ to 7.5$)$ & $4.5(0.96$ to 21$)$ & $1.8(0.42$ to 7.7$)$ & $0.50(0.12$ to 2.1$)$ \\
\hline & High & $0.075-0.75 \mathrm{mg} / \mathrm{m}^{3}$ & & $0.86(0.19$ to 3.9$)$ & $5.7(1.2$ to 27$)$ & $2.3(0.53$ to 9.9$)$ & $0.62(0.15$ to 2.6$)$ \\
\hline \multirow{3}{*}{ Ammonia } & Low & $0.0-0.5 \mathrm{ppm}$ & 43 & & 1 & 1 & \\
\hline & Medium & $0.5-1.5 \mathrm{ppm}$ & & $-\$$ & $0.40(0.07$ to 2.3$)$ & $0.32(0.03$ to 3.2$)$ & $-\$$ \\
\hline & High & $1.5-3.8 \mathrm{ppm}$ & & & $0.36(0.06$ to 2.1$)$ & $0.98(0.19$ to 5.0$)$ & \\
\hline
\end{tabular}

$\star$ Prevalence ratios with the low exposure categories as reference.

†Number of workers with complete data on the exposure variable, sex, age, and smoking.

$\neq$ Without silica.

$\$$ Model did not converge. 
Table 5 Prevalence ratios of eye and nose symptoms in Cox's regression models with two exposure variables corrected for sex, smoking, and age

\begin{tabular}{|c|c|c|c|}
\hline \multirow[b]{2}{*}{ Exposure } & \multirow[b]{2}{*}{$n^{*}$} & \multicolumn{2}{|c|}{ Prevalence ratio $(95 \%$ CI) t of exposure category } \\
\hline & & Medium $\neq$ & High $\neq$ \\
\hline \multicolumn{4}{|l|}{ Eye symptoms: } \\
\hline Fungal spores & 84 & 8.3 (0.90 to 78$)$ & $5.2(0.55$ to 50$)$ \\
\hline Inorganic dust & & 5.3 (0.60 to 47$)$ & $4.3(0.43$ to 42$)$ \\
\hline \multicolumn{4}{|l|}{ Nose symptoms: } \\
\hline Endotoxins & 89 & $1.1(0.26$ to 5.0$)$ & $2.2(0.56$ to 9.0$)$ \\
\hline Fungal spores & & $3.1(0.62$ to 16$)$ & $4.2(0.79$ to 23$)$ \\
\hline Endotoxins & 89 & $0.82(0.15$ to 4.4$)$ & $2.1(0.38$ to 12$)$ \\
\hline Dust & & $5.0(0.79$ to 32$)$ & $3.0(0.38$ to 23$)$ \\
\hline Endotoxins & 84 & $1.4(0.33$ to 5.9$)$ & $2.9(0.66$ to 13$)$ \\
\hline Silica & & $4.0(0.82$ to 20$)$ & $3.3(0.60$ to 18$)$ \\
\hline Fungal spores & 89 & $3.1(0.64$ to 15$)$ & $3.8(0.73$ to 20$)$ \\
\hline Dust & & $3.7(0.76$ to 18$)$ & $2.8(0.53$ to 15$)$ \\
\hline Fungal spores & 84 & $3.5(0.74$ to 17$)$ & $3.4(0.68$ to 17$)$ \\
\hline Silica & & $3.4(0.70$ to 16$)$ & $3.7(0.74$ to 19$)$ \\
\hline Dust & 84 & $3.3(0.64$ to 17$)$ & $2.3(0.37$ to 14$)$ \\
\hline Silica & & $3.1(0.62$ to 16$)$ & $3.7(0.63$ to 22$)$ \\
\hline
\end{tabular}

*Number of workers with complete data on both exposure variables, sex, age, and smoking. $\dagger$ Prevalence ratios with the low exposure categories as reference.

$\ddagger$ Levels of the low, medium, and high exposure categories are given in table 4 .

occurrence of nasal symptoms. No associations were found between any exposure factor and wheezing or chest tightness .

Recall bias was reduced to the lowest possible level as symptoms were recorded directly after measurements. The possibility of information bias cannot be ruled out as farmers were preoccupied with respiratory risks from exposure to dust. However, it seems less likely that farmers anticipated exposure to specific agents in the dust as no situations with excessive exposure were encountered-such as handling of mouldy hay or grain. Selection bias seems likely as asthmatic farmers may leave exposed tasks to others or they may use respiratory protection. However, the proportion of allergic farmers was only slightly lower than in the cross sectional study and allergy did not influence the exposure-response associations.

Prevalence ratios of 4-8 indicate that symptoms of the eyes and nose were increased after exposure to concentrations of $20-500 \times 10^{3}$ fungal spores $/ \mathrm{m}^{3}$ and cough after exposure to concentrations of $500-17,000 \times 10^{3}$ fungal spores $/ \mathrm{m}^{3}$ ( 8 hour TWAs). We found previously in a cross sectional study of wood trimmers in sawmills that work related nasal symptoms and cough were increased when exposed to $2 \times 10^{6}$ fungal spores $/ \mathrm{m}^{3}$ based on 2-4 week arithmetic mean exposures. ${ }^{6}$ These findings concur with the present study as the studies differ by design, exposure to other agents, and fungi. It seems not unlikely that these associations are causal as fungal spores have inflammatory properties. $^{20-22}$

An association between nasal symptoms and exposure to silica was also found with a PR of 4.5 after exposure to $0.015-0.075 \mathrm{mg}$ silica $/ \mathrm{m}^{3}$, and 5.7 after exposure to $0.075-0.75 \mathrm{mg}$ silica $/ \mathrm{m}^{3}$ Similar results have not been found in the scientific literature. As crystalline silica is strongly cytotoxic and causes acute inflammation in the airways, ${ }^{23}$ it is likely that silica can cause respiratory irritation as well. It should be noted, however, that the measurement method for silica used in this study was not a standard method and was not validated against standard methods. This method was primarily devel- oped to estimate the content of organic dust in aerosol samples with low mass. ${ }^{13}$

Endotoxin concentrations in our study were generally well above the recently proposed guidelines for no effect level for environmental endotoxin $^{2}$ of about $100 \mathrm{EU} / \mathrm{m}^{3}$ suggesting that the associations found for exposure to endotoxin might be causal. However, the strongest associations were found with fungi, indicating that exposure to fungal spores is probably more important.

It has recently been suggested that fungal $\beta(1 \rightarrow 3)$-glucans may be aetiological agents in the relation between fungal exposure and adverse respiratory health effects. ${ }^{24}$ If $\beta(1 \rightarrow 3)-$ glucans are the main components that mediate respiratory effects from exposure to fungal spores, then similar or stronger exposureresponse associations should be expected for $\beta(1 \rightarrow 3)$-glucans compared with fungal spores. However, weaker associations were found for $\beta(1 \rightarrow 3)$-glucans indicating that they can only partly explain the associations between exposure to fungal spores and work related symptoms. Alternatively, $\beta(1 \rightarrow 3)$-glucans as measured with our method may not be a valid measure for fungal $\beta(1 \rightarrow 3)$-glucans, as it also detects plant $\beta(1 \rightarrow 3)$-glucans. ${ }^{15}$ The role of plant $\beta(1 \rightarrow 3)$-glucans relative to effects on respiratory health is currently not clear.

The other fungal components that were measured, EPS-Asp/Pen, showed also weaker associations with work related symptoms compared with fungal spores. As EPS-Asp/Pen are markers for the fungal genera Aspergillus and Penicillium this indicates that spores from other species may also cause acute work related symptoms.

Exposures were found to be moderately to strongly correlated even between such biologically unrelated agents as inorganic dust and microbial agents. It is therefore not unlikely that spurious associations can be found when only a few agents are measured. In many epidemiological studies of farmers, mainly endotoxins, dust, and ammonia have been measured, ${ }^{25-29}$ and correction for exposure to other agents has usually not been applied. In the present study many agents showed increasing PRs with increasing exposure in models with a single exposure variable, but these associations became substantially weaker after adjustment for exposure to especially fungal spore. Therefore a more detailed exposure assessment is recommended to identify potential health hazards in farming.

In conclusion, exposure to several microbial and non-microbial agents were associated with acute work related symptoms of the eyes and nose as well as cough among farmers. The strongest associations were found for exposure to fungal spores, endotoxins, silica, and total dust. After adjustment for other exposures, exposure to fungal spores was found to be associated with cough and symptoms of the eyes and nose, and exposure to silica was associated with nasal symptoms. These results require further evaluation in studies with information on lung function and respiratory disease. 
The participation of the farmers is gratefully acknowledged. We thank Mette Bergum, Per Ole Huser, Kari Heldal, Lene Madsø, and Asbjørn Skogstad for assistance with the field work and analysis of samples, and Helge Kjuus for advice during the preparation of the manuscript.

1 Lacey J, Dutkiewicz J. Bioaerosols and occupational lung disease. F Aerosol Sci 1994;25:1371-404.

$2 \mathrm{ICOH}$ Committee on Organic Dust. Endotoxin in the environment: a criteria document. Int $\mathcal{F}$ Occup Environ Health 1997;3(suppl):S1-48.

3 Eduard W, Heederik D. Methods for quantitative assessment of airborne levels of noninfectious microorganisms in highly contaminated work environments. Am f Ind Hyg Assoc F 1998;59:113-27.

4 Rylander R, Persson K, Goto H, et al. Airborne $\beta$-1,3-glucan may be related to symptoms in sick buildings. Indoor Environ 1992;1:263-7.

5 Thorn J, Rylander R. Airways inflammation and glucan in a rowhouse area. Am $\mathcal{F}$ Respir Crit Care Med 1998;157:1798rowh.

6 Eduard W, Sandven P, Levy F. Exposure and IgG antibodies to mold spores in wood trimmers: exposure-response relationships with respiratory symptoms. Appl Occup Environ Hyg 1994;9:44-8.

7 Melbostad E, Eduard W, Skogstad A, et al. Exposure to bacterial aerosols and work-related symptoms in sewage workers. Am f Ind Med 1994;25:59-63.

8 Houba R, Heederik DJJ, Doekes G, et al. Exposuresensitization relationship for $\alpha$-amylase allergens in the baking industry. Am F Respir Crit Care Med 1996;154:130 6.

9 Thorn J, Beijer L, Rylander R. Airways inflammation and glucan exposure among household waste collectors. Am $\mathcal{F}$ Ind Med 1998;33:463-70.

10 Melbostad E, Eduard W, Magnus P. Chronic bronchitis in farmers. Scand F Work Environ Health 1997;23:271-80.

11 Melbostad E, Eduard W, Magnus P. Determinants of asthma in a farming population. Scand $\mathcal{F}$ Work Environ Health 1998;24:262-9.

12 Eduard W, Sandven P, Johansen BV, et al. Identification and quantification of mould spores by scanning electron microscopy (SEM): analysis of filter samples collected in Norwegian saw mills. Ann Occup Hyg 1988;32:447-55.

13 Skogstad A, Madsø L, Eduard W. Classification of particles from the farm environment by automated sizing, counting and chemical characterisation with scanning electron microscopy-energy dispersive spectrometry. Fournal of Environmental Monitoring 1999;1:379-82.

14 Heldal K, Skogstad A, Eduard W. Improvements in the quantification of airborne microorganisms in the farm
environment by epifluorescence microscopy. Ann Occup Hyg 1996;40:437-47.
15 Douwes J, Versloot P, Hollander A, et al. Influence of various dust sampling and extraction methods on the measurement of endotoxin. Appl Environ Microbiol 1995;61:1763-9.

16 Douwes J, Doekes G, Monteijn R, et al. Measurement of $\beta(1 \rightarrow 3)$-glucans in the occupational and home environment with an inhibition enzyme immunoassay. Appl Environ Microbiol 1996;62:3176-82.

17 Douwes J, van der Sluis B, Doekes G, et al. Fungal extracelular polysaccharides in house dust as a marker for exposure to fungi: relations with culturable fungi, reported Tome dampness and respiratory symptoms. 7 Allergy Clin Immunol 1999;103:494-500.

$18 \mathrm{Mehl}$ R. Occurrence of mites in Norway and the rest of Scandinavia. Allergy 1998;53(48 suppl):S28-35.

19 Thompson ML, Myers JE, Kriebel D. Prevalence odds ratio or prevalence ratio in the analysis of cross sectional data: what is to be done? Occup Environ Med 1998;55:272-7.

20 Thurston JR, Cysewski SJ, Richard JL. Exposure of rabbits to spores of Aspergillus fumigatus or Penicillium sp: survival of fungi and microscopic changes in the respiratory and gastrointestinal tracts. Am F Vet Res 1979;40:1443-9.

21 Fogelmark B, Lacey J, Rylander R. Experimental allergic alveolitis after exposure to different microorganisms. International fournal of Experimental Pathology 1991;72:387-95.

22 Shahan TA, Sorenson WG, Lewis DM. Superoxide anion production in response to bacterial lipopolysaccharide and fungal spores implicated in organic dust toxic syndrome. Environ Res 1994;67:98-107.

23 Hilt B. Crystalline silica. In: Beije B, Lundberg P, eds. Criteria documents from the Nordic expert group 1993. Solna, Sweden: National Institute of Occupational Health, 1993. (Arbete och Hälsa 1993:35.)

24 Rylander R. Investigations of the relationship between disease and airborne $\beta(1 \rightarrow 3)$-glucan in buildings. Mediators of Inflamm 1997;6:275-7.

25 Thelin A, Tegler O, Rylander R. Lung reactions during poultry handling related to dust and bacterial endotoxin levels. Eur f Respir Dis 1984;65:266-71.

26 Haglind P, Rylander R. Occupational exposure and lung function measurements among workers in swine confinefunction measurements among workers in swin
ment buildings. F Occup Med 1987;29:904-7.

27 Preller L, Heederik DJJ, Boleij JSM, et al. Lung function and chronic respiratory symptoms of pig farmers: focus on exposure to endotoxins and ammonia and use of disinfectants. Occup Environ Med 1995;52:654-60.

28 Schwartz DA, Donham KJ, Olenchock SA, et al. Determinants of longitudinal changes in spirometric function among swine confinement operator and farmers. Am $\mathcal{F}$ Respir Crit Care Med 1995;151:47-53.

29 Reynolds SJ, Donham KJ, Whitten P, et al. Longitudinal evaluation of dose-response relationships for environmental exposures and pulmonary function in swine production workers. Am f Ind Med 1996;29:33-40.

\section{ANSWERS}

(1) (a) False

(b) False: they are based either on an $8 \mathrm{~h}$ TWA or a 15 minute reference period

(c) False: $\mathrm{COSHH}$ requires employers to consider seven basic measures

(d) True

(e) True

(2) (a) True

(b) False: many OESs are set on the basis of data from studies in animals

(c) False: only a NOAEL is needed

(d) True

(e) True

(3) (a) False: set by HSC

(b) True

(c) True

(d) True

(e) False: around 600

(4) (a) False

(b) True

(c) (1) False

(2) True

(d) (1) False

(2) True

(e) True

(5) (a) (1) False

(2) True

(3) True

(b) False

(c) True 